International Journal of Translational

Medical Research and Public Health (2020), Volume 4, Issue 2, II 2 - 122

\begin{tabular}{|c|c|c|}
\hline 1 & & $\begin{array}{l}\text { INTERNATIONAL JOURNAL OF TRANSLATIONAL } \\
\text { MEDICAL RESEARCH AND PUBLIC HEALTH } \\
\text { ISSN 2576-9502 (Online) }\end{array}$ \\
\hline I]TMRPH & Available online at www.ijtmrph.org & $\begin{array}{l}\text { ISSN 2576-9499 (Print) } \\
\text { DOI: I0.21 | 06/ijtmrph.|6| }\end{array}$ \\
\hline
\end{tabular}

\title{
ORIGINALARTICLE | UNDER-FIVE MORTALITY Determinants of Under-Five Mortality in Ghana: Evidence from the Ghana Demographic and Health Survey
}

\author{
Albert Apotele Nyaaba, MPhil; ${ }^{1,2 \varangle}$ Augustine Tanle, $\mathrm{PhD} ;^{2}$ Louis Kobina Dadzie, MPhil; ${ }^{2}$ \\ Matthew Ayamga, $\mathrm{MSc}^{3}$ \\ 'Youth Harvest Foundation, Bolgatanga, Ghana; ${ }^{2}$ Department of Population and Health, University of Cape Coast, Cape Coast, Ghana; ${ }^{3}$ nformation \\ Technology Chair Group, Wageningen University \& Research, 6708 PB Wageningen, Netherlands \\ $\square$ Corresponding author email: albertnyaabal3@yahoo.com
}

\section{ABSTRACT}

Background and Objectives: This study aims to investigate the strength of the association between socio-economic, maternal and environmental determinants and under-five mortality in Ghana.

Methods: We utilized data from the 2014 Ghana Demographic and Health Survey, a population-based cross-sectional study, which included 4I5I children born alive to women aged I5-49 years. The primary outcome variable was under-five mortality. Descriptive statistics and multivariate logistic regression were applied to assess the relationship and relative association of the independent variables with the outcome variable.

Results: Children of women with secondary education and above and women within the middle wealth status were 0.593 and 0.886 less likely to experience under five deaths compared to women with no education and women of low wealth status (OR=0.593; $95 \% \mathrm{Cl} I .690$ to $2.063 ; \mathrm{p}<0.0 \mathrm{I})(\mathrm{OR}=0.886 ; 95 \%$ $\mathrm{Cl}$ I.48 to I.63; $\mathrm{p}<0.0 \mathrm{I})$. Women who had their first birth at age $20-29$ years were 0.764 less likely to experience under-five deaths compared to those aged I5- I9 years $(\mathrm{OR}=0.764 ; 95 \% \mathrm{Cl} 0.994$ to I. $19 \mathrm{I}$; $\mathrm{P}<0.0 \mathrm{I})$. Children born in households with pit toilets were more likely $(\mathrm{OR}=1.5 \mathrm{I} ; 95 \% \mathrm{Cl} \mathrm{I} .20$ to 2.30 ; $\mathrm{P}<0.0 \mathrm{I})$ to die before age five compared to children born in households with flushed toilet. Women who used bore hole /well water were more likely $(O R=1.686 ; 95 \% \mathrm{Cl} 2.94$ to 3.01 ; $p<0.05)$ to experience under-five deaths compared to women who used piped water.

Conclusion and Implications for Translation: This study identified the determinants that significantly predicted under-five deaths and the magnitude of the influence on under-five deaths in Ghana. It accentuates the need for increased maternal education, delayed child bearing, provision of improved drinking water and toilet facilities to reduce under-five deaths in Ghana.

Key words: • Socio-economic • Maternal health - Child health • Environmental factors • Under-five mortality • Ghana $•$ Demographic and Health Survey $•$ DHS

Copyright @ 2020 Nyaaba, et al. Published by Global Health and Education Projects, Inc. This is an open-access article distributed under the terms of the Creative Commons Attribution License CC BY 4.0. 


\section{Background}

Under-five mortality is a major indicator of child health and the overall development of every nation because it depicts the social, economic and environmental conditions in which children are born or live including their health care.' Underfive mortality is defined as the risk of a child dying before completing five years of age. ${ }^{2}$ The $21^{\text {st }}$ century has witnessed the most dramatic decline in under-five mortality in almost all countries of the world, regardless of initial levels, socio-economic circumstances and development strategies. ${ }^{3}$ Globally under-5 mortality rate has fallen from 90.6 deaths per 1000 livebirths in 1990 to 42.5 in $2015 .^{4}$

However, more than 10.8 million children younger than five years die every year mostly from preventable causes. ${ }^{3}$ These leading causes of death among children under five have been attributed to preterm birth complications, acute respiratory infections, intrapartum-related complications, congenital anomalies, diarrhea and malaria. ${ }^{5}$ Between 2016 and 2030, 94.4 million children are projected to die before age five years if the 2015 mortality rate remains constant in each country and 68.8 million would die if each country continues to reduce its mortality rate at the pace estimated from 2000 to 2015. ${ }^{4}$ The overwhelming majority of these deaths occurred in the poorest regions and countries of the world, and in the most underprivileged areas within countries. ${ }^{6}$ Under five deaths is still a major public health problem in developing countries, especially in Sub-Saharan Africa where the rates have been persistently higher compared to other regions from 1990 to 2016. However, all countries have been bench marked to reduce under-five mortality to at least 25 deaths per 1000 live-births by 2030 according to the Sustainable Development Goal (SDG) 3 target $2 .^{8}$

According to estimates from the Global Burden of Disease (GBD), 2017 SDG Collaborators, many countries are on track for achieving the target of at least 25 deaths per 1000 livebirths by 2030 . However, about 31 countries would need to achieve annual rates of decline from 2015 to 2030 that are about two to ten times higher than what was recorded for
1990-2015 in order to achieve this goal. ${ }^{9}$ In spite of the significant decline in global under-five mortality, the rates remain high in Sub-Saharan Africa where many countries, such as Ghana, failed to meet the Millennium Development Goals (MDGs) Goal 4 which aimed at achieving a two-thirds reduction in the under-five mortality rate by 2015 . For example, in 2015, the under-five mortality rate in Sub-Saharan Africa was 79 deaths per 1000 live births compared to the global rate of $4 \mathrm{I}$ deaths per 1000 live births in the referenced year. ${ }^{4}$

Within sub-Saharan Africa, Ghana in particular, experienced a slow but nevertheless, steady decline in its under-five mortality rate over the past 40 years with an accelerated reduction since the year 2000. Despite the decline, under-five mortality rate in Ghana is still high with a rate of 60 deaths per $\mathrm{I}, 000$ live births as of 20I4. This fell short of the target set in the Ghana Under-five Child Health Policy 2007-20/5 which targeted a reduction in under-five mortality to 40 deaths per 1000 live births by $2015 .^{10}$ Though Ghana has made some significant progress in under-five mortality, the improvement is widely due to governments' commitment to improved services, poverty reduction and various new targets of public health initiatives that have improved access to water and sanitation, maternal health and child health." Other programs included the community health planning services program, (CHPS) established in 2006 which sought to provide access, quality and equitable health care services and the National Health Insurance Scheme (NHIS) established in 2003 with the goal of providing financial access to health care services. ${ }^{12}$

Despite all these interventions, under-five mortality remains high. A recent study of 46 African countries showed that Ghana is among the eight countries not making enough efforts towards reducing under five mortality. ${ }^{13}$ Further investigation into the factors influencing the under-five mortality is therefore warranted. In order to achieve the SDGs 3.2, understanding of determinants of underfive mortality and the implementation of appropriate intervention is expected from countries with high under five mortality. In Ghana, a few studies have examined the factors influencing under five mortality. 
Tette et al. ${ }^{14}$ conducted a health facility-based case control studies in Accra, Ghana to examine the risk factors associated with under five mortality in the country. This study was not representative of under five deaths in the general Ghanaian population. Quansah et al. ${ }^{15}$ conducted a systematic review on social factors influencing under-five mortality; Kanmiki et al. ${ }^{16}$ investigated the socio-economic and demographic determinants of under-five mortality, whilst Aheto ${ }^{7}$ studied predictive model and determinants of under-five mortality. Thus, there is limited information published on socio-economic, maternal and environmental factors influencing under five mortality in Ghana.

To guide our study, we adopted a conceptual framework by Mosley and Chen ${ }^{17}$ on socio-economic and proximate determinants of mortality. According to this framework, the socioeconomic factors such as work status, wealth quintile, and education indirectly affect the under-five mortality through the operations of the proximate determinants of maternal, environmental, nutritional, injury and behavioral factors. The limitation of this framework, however, was that not all the variables are applicable in all settings hence the need for the adaptation (Figure I).

To assess child survival programs, the socioeconomic and proximate determinants of underfive mortality should be measured in a populationbased research. Based on the on-going debate on the influence of particular socio-economic, maternal and environmental characteristics of mothers on under-five mortality in Ghana, this paper sought to investigate further the socio-economic, maternal and environmental factors that influence under five mortality and the magnitude of their influence in Ghana using a nationally representative dataset.

\section{Method}

\section{I. Study Design and Sampling}

This study used data from the 2014 Ghana Demographic and Health Survey (GDHS) conducted in Ghana every five years. The GDHS collects nationally representative data on women of childbearing age (15-49) years and their children. ${ }^{10}$

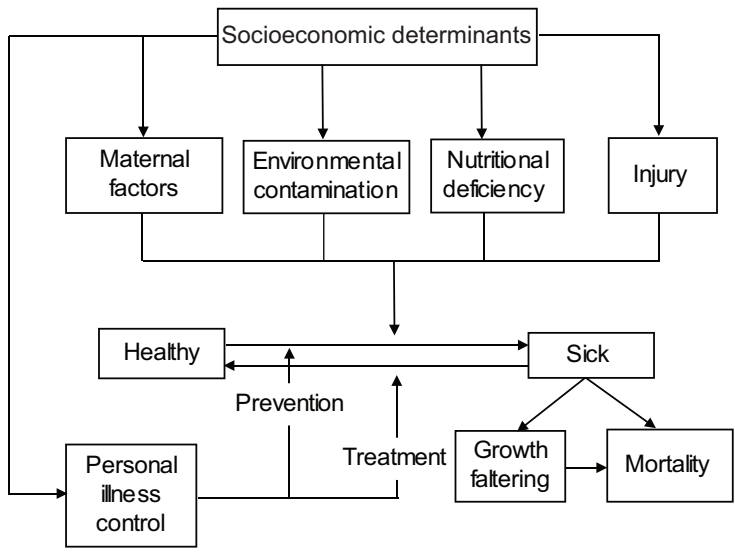

Figure I: Proximate determinants of child survival

Source: Adapted from Mosley and Chen, 1984

The data were obtained from the DHS MEASURE Program (Measure DHS) which is readily available online and contain information which covers a range of population, health, fertility and nutrition indicators such as childhood mortality, maternal and child health, use of family planning methods, nutritional status of women and children as well as household socioeconomic variables. ${ }^{10}$ The GDHS focuses on child and maternal health and is designed to provide adequate data to monitor the population and health situation in Ghana. It employed a two-stage sample design to select respondents for the study. The 2014 round of survey interviewed 9,396 women aged within I5-49 years from I2,83 I households covering 427 clusters comprising 216 and 211 urban and rural areas respectively. It had a response rate of 97 percent." Detailed survey methods are published and available on line." Data on children less than five years who were born five years preceding the survey were 4,151 on which the analyses were based. Complete birth histories were collected including month and year of each child's birth and death. These data were used to identify the number of children born in the last five years and age at death.

\subsection{Measures}

The dependent variable for the study was underfive mortality, coded "I" if a child died before the fifth birthday and 0 if otherwise. The responses were dichotomously coded as Yes or No.The determinants examined in the study were selected based on the 
literature and included age of mother at first birth, grouped as 15-19, 20-29 and 30-39 years; mother's level of education, categorized as no education, primary education and secondary education and above; wealth status grouped as low, middle and high; birth order of child grouped as I, 2-3, and 4+; birth interval as $<24$ month and $>24$ months; place of delivery put into home, public facility, private facility and others; type of toilet recoded as flushed, pit toilet and others; source of drinking water was also recoded as piped water, bore hole and others.

\subsection{Statistical Analysis}

Descriptive statistics as well as chi-square test were used to examine the distribution of underfive mortality by the selected characteristics, whilst binary logistic regression was employed to identify significant covariates associated with the probability of dying before age 5 years. A sequential modelling technique was adopted to examine the extent to which the selected socioeconomic, maternal and environmental factors contribute to explain the variation in the probability of a child dying before age 5. Model I, accounting for only the socioeconomic factors (educational level, work status and wealth) was then fitted. Model 2 included the maternal factors (age at first birth, birth order, birth interval and place of delivery), whilst the environmental factors (toilet facility and source of drinking water) were added in Model 3.The models conducted were expressed as odds ratios at the corresponding $95 \%$ confidence intervals. In computing the odds ratio for each category of the independent variables, multicollinearity was checked with variance-inflation factor (VIF) and a mean value of $\mathrm{I} .26$ found indicating the absence of multi collinearity (VIF above 10 indicates the presence of multicollinearity). ${ }^{18}$ The Ethics Review Committee, Ghana Health Service, Accra, Ghana and the Ethics Committee of ICF Macro in Calverton, USA gave the ethical approval to conduct GDHS which was used in this study.

\section{Results}

\section{I. Characteristics of the Population}

General characteristics of the population are shown in table I below. About 9,396 women aged 15-49 years were interviewed from 12, 83। households. About $47 \%$ of the women had secondary education and above with almost $80 \%$ categorized as currently working. More than half $(52 \%)$ of the women were found in low wealth quintile. Approximately three percent of the live births died before age five.

\subsection{Relationship between the Determinants and Under-five Deaths}

Table I shows the results of chi-square analysis that examined the relationship between the determinants and the outcome. For the socioeconomic determinants, maternal education had significant relationship with under-five deaths $\left(X^{2}=2.0432\right.$; $p=0.036)$. The highest $(3.2 \%)$ proportion of underfive deaths, were observed among mothers with no education. Wealth status was found significant with under-five deaths $\left(X^{2}=0.8928 ; p=0.048\right)$ with children born to mothers in middle wealth quintile households recording $3.5 \%$ under-five deaths. Maternal determinants indicated that birth order was significantly associated with under-five mortality $\left(X^{2}=3.45591 ; p=0.027\right)$. With respect to environmental determinants, type of toilet facility was significantly associated with under-five deaths $\left(X^{2}=5.2702 ; p=0.026\right)$. However, most (3.2\%) underfive deaths were accounted for by households using pit toilet facility (Table I).

\subsection{Socioeconomic Status, Maternal and Environmental Determinants and Under-five Deaths}

Table 2 shows results of multivariate logistic regression (sequential model) that examined association between socio-economic, maternal and environmental factors and under-five death. Conducted to identify the determinants of underfive mortality, the model indicated pseudo $R^{2}$ values for the three models considered in the analyses as model I (socio-economic factors) - 0.103; model II (maternal factors) - 0.I70; and model III (socio-economic factors, maternal factors and environmental factors) -0.270 . The fit of a model was also expressed by the coefficient of regression (pseudo $\mathrm{R}^{2}$ ). It showed that model III best explained the contribution of the covariates to under five mortality. The results indicated that in model I, 
Nyaaba et al. International Journal of Translational Medical Research and Public Health (2020), Vol. 4, No. 2, I I 2- I 22

Table I: Univariate analysis of the determinants of under-five mortality by explanatory variables.

\begin{tabular}{|c|c|c|c|}
\hline Variable & Alive (\%) & Dead (\%) & Total \\
\hline Children under-five & 4031 & 120 & $4|5|$ \\
\hline Highest education & $X^{2}=2.0432 \quad d=2$ & $\operatorname{Pr}=0.036$ & \\
\hline No education & 96.8 & 3.2 & $1355(100)$ \\
\hline Primary education & 97.8 & 2.2 & $857(100)$ \\
\hline Secondary education above & 97 & 3 & $1960(100)$ \\
\hline Work status & $X^{2}=0.0532 d=I$ & $P r=0.818$ & \\
\hline Currently working & 96.9 & 3.1 & $854(100)$ \\
\hline Not working & 96.9 & 3.1 & $3123(100)$ \\
\hline Wealth status & $X^{2}=0.8928$ & $P r=0.048$ & \\
\hline Low & 97.1 & 2.9 & $2137(100)$ \\
\hline Middle & 96.5 & 3.5 & $797(100)$ \\
\hline High & 97.3 & 2.7 & $1217(100)$ \\
\hline Place of delivery & $X^{2}=1.5775 \quad d=3$ & $\operatorname{Pr}=0.665$ & \\
\hline Home & 97.4 & 2.6 & $1124(100)$ \\
\hline Public facility & 96.9 & 3.1 & $2738(100)$ \\
\hline Private facility & 97.4 & 2.6 & $272(100)$ \\
\hline Other & 93.3 & 6.7 & $16(100)$ \\
\hline Age at first birth & $X^{2}=1.5903 \quad d=2$ & $\operatorname{Pr}=0.462$ & \\
\hline $15-19$ & 97.4 & 2.6 & $1838(100)$ \\
\hline $20-29$ & 96.9 & 3.1 & $2167(100)$ \\
\hline $30-39$ & 95.7 & 4.3 & $144(100)$ \\
\hline Birth order & $X^{2}=3.4591 \quad d=2$ & $\operatorname{Pr}=0.027$ & \\
\hline 1 & 96.4 & 3.6 & $929(100)$ \\
\hline $2-3$ & 98.3 & 1.7 & $1,526(100)$ \\
\hline $4+$ & 97 & 3 & $1,694(100)$ \\
\hline Birth interval & $X^{2}=0.3620 \quad d=I$ & $P r=0.470$ & \\
\hline$<24$ Months & 96.7 & 3.3 & $411(100)$ \\
\hline$>24$ Months & 97.3 & 2.7 & $2796(100)$ \\
\hline Type of toilet & $X^{2}=5.2702 d=4$ & $P r=0.026$ & \\
\hline Flush toilet & 98 & 2 & $560(100)$ \\
\hline Pit toilet & 96.8 & 3.2 & $2218(100)$ \\
\hline Other & 97.1 & 2.9 & $1,371(100)$ \\
\hline Source of drinking water & $X^{2}=4.1095 \quad d=2$ & $\operatorname{Pr}=0.350$ & \\
\hline Piped water & 96.5 & 3.5 & $1140(100)$ \\
\hline Well/bore hole & 97 & 3 & $1396(100)$ \\
\hline Other & 97.5 & 2.5 & $1,613(100)$ \\
\hline
\end{tabular}

Source: Data computed from the GDHS, 2014

education and wealth status were significantly associated with under five mortality. In model II, wealth, age at first birth, place of delivery were significant whilst in model III, education, wealth status, age at first birth, birth order, place of delivery, type of toilet facility and source of drinking water were all significant at different confidence intervals. This implies that children born to women with secondary education and above were $59 \%$ less likely to experience under five mortalities compared 
Table 2: Multivariate Analysis

\begin{tabular}{|c|c|c|c|}
\hline \multirow[t]{2}{*}{ Variables } & Model I Odds ratio & Model II Odds ratio & Model III Odds ratio \\
\hline & [Confidence Interval] & [Confidence Interval] & [Confidence Interval] \\
\hline \multicolumn{4}{|c|}{ Socioeconomic determinants } \\
\hline \multicolumn{4}{|c|}{ Education } \\
\hline No education & Ref. & Ref. & Ref. \\
\hline \multirow[t]{2}{*}{ Primary } & 1.511 & 1.805 & 1.777 \\
\hline & {$[0.860,2.655]$} & {$[0.929,3.506]$} & {$[0.911,3.466]$} \\
\hline \multirow[t]{2}{*}{ Secondary+ } & $0.703^{*}$ & 0.246 & $0.593 * *$ \\
\hline & {$[0.678,1.699]$} & {$[0.725,2.144]$} & {$[1.690,2.063]$} \\
\hline \multicolumn{4}{|l|}{ Work status } \\
\hline Currently working & Ref. & Ref. & Ref. \\
\hline \multirow[t]{2}{*}{ Not working } & 1.046 & 1.225 & 1.175 \\
\hline & {$[0.671, I .63 I]$} & {$[0.701,2.143]$} & {$[0.671,2.060]$} \\
\hline \multicolumn{4}{|l|}{ Wealth } \\
\hline Low & Ref. & Ref. & Ref. \\
\hline \multirow[t]{2}{*}{ Middle } & $0.812 *$ & $0.760 *$ & $0.886 * *$ \\
\hline & {$[0.499,1.322]$} & {$[0.430,1.343]$} & {$[0.481,1.632]$} \\
\hline \multirow[t]{2}{*}{ High } & 1.040 & 1.219 & 1.182 \\
\hline & {$[0.636, I .700]$} & {$[0.644,2.308]$} & {$[0.578,2.419]$} \\
\hline \multicolumn{4}{|c|}{ Maternal determinants } \\
\hline \multicolumn{4}{|l|}{ Age at first birth } \\
\hline 15-19Years & & Ref. & Ref. \\
\hline \multirow[t]{2}{*}{ 20-29 Years } & & $0.778 *$ & $0.764 * *$ \\
\hline & & {$[0.499,1.214]$} & {$[0.490,1.191]$} \\
\hline \multirow[t]{2}{*}{ 30-39 Years } & & 0.858 & 0.770 \\
\hline & & {$[0.197,3.739]$} & {$[0.176,3.38 I]$} \\
\hline Birth order & & Ref. & Ref. \\
\hline 1 & & $1.569[0.881,2.79]$ & $1.343[0.848,2.125]$ \\
\hline $2-3$ & & 0.737 & $0.662^{* *}$ \\
\hline $4+$ & & {$[0.466,1.166]$} & {$[1.710,2.24]$} \\
\hline \multicolumn{4}{|l|}{ Birth interval } \\
\hline & & Ref. & Ref. \\
\hline$>24$ Months & & 0.802 & 1.262 \\
\hline$<24$ Months & & {$[0.438, I .468]$} & {$[0.688,2.315]$} \\
\hline \multicolumn{4}{|l|}{ Delivery place } \\
\hline Home & & Ref. & Ref. \\
\hline \multirow[t]{2}{*}{ Public facility } & & $0.65 \mathrm{I} * *$ & $0.670 * * *$ \\
\hline & & {$[0.384, I .103]$} & {$[1.395,2.136]$} \\
\hline \multirow[t]{2}{*}{ Private facility } & & 0.239 & 0.145 \\
\hline & & {$[0.351,4.370]$} & {$[0.323,4.053]$} \\
\hline \multirow[t]{2}{*}{ Others } & & 0.295 & 0.320 \\
\hline & & {$[0.0363,2.399]$} & {$[0.0390,2.617]$} \\
\hline
\end{tabular}


Table 2: (Continued)

\begin{tabular}{|c|c|c|c|}
\hline \multirow[t]{2}{*}{ Variables } & \multirow{2}{*}{$\frac{\text { Model I Odds ratio }}{\text { [Confidence Interval] }}$} & \multirow{2}{*}{$\frac{\text { Model II Odds ratio }}{\text { [Confidence Interval] }}$} & \multirow{2}{*}{$\begin{array}{l}\text { Model III Odds ratio } \\
\text { [Confidence Interval] }\end{array}$} \\
\hline & & & \\
\hline \multicolumn{4}{|c|}{ Environmental determinants } \\
\hline \multicolumn{4}{|c|}{ Toilet facility } \\
\hline Flushed & & & Ref. \\
\hline \multirow[t]{2}{*}{ Pit } & & & $1.512 * *$ \\
\hline & & & {$[1.201,2.303]$} \\
\hline \multirow[t]{2}{*}{ Others } & & & 0.505 \\
\hline & & & {$[0.177, I .440]$} \\
\hline \multicolumn{4}{|c|}{ Source of drinking water } \\
\hline Piped & & & Ref. \\
\hline \multirow[t]{2}{*}{ Borehole } & & & $1.686 *$ \\
\hline & & & {$[2.942,3.015]$} \\
\hline \multirow[t]{2}{*}{ Others } & & & 1.494 \\
\hline & & & {$[0.874,2.553]$} \\
\hline $\mathrm{N}$ & $4|5|$ & 4151 & $4|5|$ \\
\hline Pseudo $r^{2}$ & 0.103 & 0.170 & 0.270 \\
\hline
\end{tabular}

Exponentiated coefficients; $\mathrm{Cl}=$ Confidence Interval; 95\% Confidence Intervals in brackets Ref.=Reference category

Source: Data computed from the GDHS 2014

to children born to women with no education (OR=0.593; 95\% Cl I.690 to 2.063; $\mathrm{p}<0.05$ ). Children born to women who gave birth to their first child at age $20-29$ years were $76 \%$ less likely to die before age five compared to those I5-19 years $(O R=0.764 ; 95 \% \mathrm{Cl} 0.940$ to I.I9I; $p<0.01)$. On wealth status, children born to household within the middle wealth status were almost $89 \%$ likely of dying before age five compared to children born to low wealth status households $(O R=0.886 ; 95 \% \mathrm{Cl} 0.48 \mathrm{I}$ to I.632; $\mathrm{p}<0.01$ ). Regarding birth order, children born to order 4+ were $66 \%$ less likely to experience under five deaths $(\mathrm{OR}=0.662 ; 95 \% \mathrm{Cl} \mathrm{I} .7 \mathrm{I} 0$ to 2.24 ; $\mathrm{p}<0.0 \mathrm{I}$ ) compared to birth order I. The likelihood of under five deaths among children born in the public health facility was $67 \%$ less $(O R=0.670 ; 95 \% \mathrm{Cl}$ I.395 to 2.I36; $\mathrm{p}<0.00 \mathrm{I}$ ) compared to those born at home. Conversely, children born to households using pit toilet were $5 \mathrm{I} \%(\mathrm{OR}=0.5 \mathrm{I}$; $95 \% \mathrm{Cl} \mathrm{I} .20 \mathrm{I}$ to 2.303 ; $\mathrm{p}<0.0 \mathrm{I})$ more likely to die before age five compared to children in households using flushed toilet. About $69 \%$ of children born to households with borehole as their main source of drinking water were more likely to die compared to children of household using piped water $(\mathrm{OR}=\mathrm{I} .686 ; 95 \% \mathrm{Cl} 2.942$ to 3.015 ; $\mathrm{P}<0.05$ ) (see Table 2).

\section{Discussion}

This study examined the influence of socio-economic, maternal and environmental characteristics on mothers of children who experienced under-five mortality in Ghana. The bivariate analysis in table I showed that education, birth order and type of toilet facility used had significant relationship with under five mortality. Results of multivariate analysis indicated that multiplicity of factors are involved in under-five mortality. Education was significantly associated with under-five mortality. Children of mothers who had secondary education and above were less likely to experience under-five mortality compared to mothers with no education. This finding is consistent with those by Worku ${ }^{19}$ that under-five mortality rates were higher among less-educated mothers compared with mothers who have higher levels of education. This could be attributed to the fact that mothers who are educated are more likely to take their children to a health center for preventive and curative care to avoid the delays as posited in the three-delay model. ${ }^{20}$ In view of this, the governments free senior high school policy introduced since $2017 / 2018$ academic year should be managed well in order that the females will hugely benefit from it. ${ }^{21}$ 
Regarding wealth status, the findings showed that, children born to mothers from households within the middle wealth status were of less likelihood of under-five mortality compared to those of low wealth status. These findings affirmed what Doctor et al., ${ }^{22}$ found that children in the low wealth status households were more likely to die before reaching their fifth birthday compared to those in the middle and high wealth households. This is because rich households are able to afford food that is necessary for under-five growth which improves their immunity and help in reducing infections which are a major threat to the child's survival. They could also access quality healthcare which is important for child survival but not the case for households in low wealth status. The effects of age at first birth on child health have been a subject of extensive discourse in literature. Findings of this study revealed that children born to mothers aged 30-39 years were less likely to experience underfive mortality compared to mothers aged 15-19 years. This confirms studies by Kayode et al., ${ }^{23}$ that children of mothers who started children bearing at an early age were more prone to experience underfive mortality compared to those that commenced child bearing at an older age. This may be explained by the fact that mothers of this age group are mature, have access to health care and tend to utilize health information. Therefore, the Adolescent Health Service Policy and Strategy 2016-2020 should be refreshed and properly implemented emphasizing on contraception and abstinence so as to delay child bearing. ${ }^{24}$

Contrary to previous studies by Hossain et al., ${ }^{25}$ that birth order 4+ have higher risk of mortality compared to lower birth orders, this study found that children born to order 4+ were less likely to die before age five compared to order I, perhaps mothers of these children are mature (20-39), experienced and make some advance preparations before delivery.

In connection with place of delivery, children who were born in public facilities were less likely to die before reaching their fifth birth day compared to those born at home. This finding supports studies by Sahu et al. ${ }^{26}$ that delivery at a health facility reduces the risk of under-five mortality. As a result, the free maternal health policy was implemented under the National Health Insurance Scheme in Ghana in 2008. ${ }^{27}$ The policy guarantees all pregnant women to have free registration with the National Health Insurance Scheme (NHIS) after which they would be entitled to free services throughout pregnancy, childbirth and three months postpartum. The reason being that, health facilities have professional service providers who take good care of the health needs of both the mother and the newborn. Studies have shown that women's decisions about the choice of place of birth either at the facility or home are influenced by several factors, ranging from demographic, socio-economic circumstances, cultural to health system factors. ${ }^{28}$ In attempt to address this, the Community-based Planning and Health Services was introduced in 1994 with the aim of bringing health care close to communities. ${ }^{29} \mathrm{On}$ source of drinking water, children born to mothers from households using borehole/well as their major source of drinking water were $67 \%$ more likely to experience under-five mortality compared to those children of households using piped water. This supports findings by Kayode et al. ${ }^{23}$ that availability of piped water in a dwelling has a positive influence on child survival. This may be partly because the immune systems of children under-five are not mature and strong as those of adults to deal with infections.

The risk of under-five mortality to children from households with no toilet facility were more likely compared to households with flushed toilet. This finding supports previous studies that children born to households with toilet facility have reduced relative risks of under-five mortality compared to their counterparts born to households with no toilet facility. ${ }^{30}$ Probably the lack of improved toilet facility creates unhygienic human waste disposal thereby leading to infections such as cholera, repeated diarrhea, etc. which gives rise to malnutrition, poor health and subsequently under-five death. Though, the study did not find work status and birth interval significant, the odds ratio showed that non-working women were more likely to have their children die before age five and 
children born to women of birth interval $>24$ months were less likely to die before celebrating their fifth birthday.

\section{I. Strengths and Limitations of the Study}

This study used nationally representative data from the 2014 Ghana Demographic and Health Survey with robust sampling technique, standardized data collection procedures, high quality interviewer training and high response rate. The biases in the data set were fairly random, the aggregate estimates of indicators were fairly adequate. The study assessed the determinants of under-five mortality on the basis of variables captured in the GDHS data set. Limitations of the survey data includes misclassification since most of the health information were based on women reports. The survey data was also subject to age misreporting since respondents could heap or report their ages on the basis of digit preference.

\section{Conclusions and Implications for Translation}

This study adds to the understanding of drivers of under-five mortality in Ghana. The evidence of greater risk of under-five mortality associated with early child birth, low wealth status, no education, use of pit toilet facility, lower birth order and use of unimproved source of drinking water underscore the need for toiler made interventions to address these factors in Ghana. It is recommended that government scale up the WASH toilet project to all part of the country. There is also an agent need for portable water especially in the rural communities in Ghana. On the basis of the findings, it is recommended that policy makers should not just encourage education of females (15-19 years) but rather emphasize on higher female education beyond primary school level to delay early child bearing. Also, there is the need to promote health facility delivery since it reduces the risk of under-five mortality as a result of the availability of professional service providers who take good care of the health needs of both the mother and the newborn. Findings of this study will inform and strengthen appropriate national policies and intervention strategies aimed at reducing underfive mortality in Ghana in our efforts to achieve the
SDG 3.2. It will be worthwhile to research further using qualitative studies to explore the perception of women on why these factors influence under-five mortality in Ghana.

\section{Ethical Considerations}

Competing Interest: None. Funding/Support: The publication of this article was partially supported by the Global Health and Education Projects, Inc. (GHEP) through the Emerging Scholars Grant Program (ESGP). The information, contents, and conclusions are those of the authors' and should not be construed as the official position or policy of, nor should any endorsements be inferred by ESGP or GHEP. Ethics Approval: Ethics Review Committee, Ghana Health Service, Accra, Ghana and the Ethics Committee of ICF Macro in Calverton, USA gave the ethical approval to conduct GDHS. Acknowledgment: The authors are thankful to Measure DHS for granting them permission to use the GDHS data set.

\section{Key Messages}

Health facility delivery is critical to reducing under-five mortality.

- Households' access to portable water reduces the risk of under-five mortality.

- Women with higher education delay child bearing.

\section{References}

I. McGuire JW. Basic health care provision and under-5 mortality: a cross-national study of developing countries. World Development, 2006; 34(3), 405-425.

2. World Health Organization. Global health observatory (GHO) data, Report. from https://www.who.int/gho/ en/.Accessed on March 14, 2019.

3. Ahmad OB, Lopez AD, Inoue M. The decline in child mortality: a reappraisal. Bulletin of the World Health Organization, 2000; 78, II75-1191.

4. You D, Hug L, Ejdemyr S, Beise J, Perez-Escamilla R, Moran VH, Petchesky RP. Levels and trends in child mortality. Estimates developed by the UN Interagency Group for Child Mortality Estimation (IGME). Report 20I5. Matern Child Nutr. 20 16;52(3): I-6.

5. Liu L, Oza S, Hogan D, Chu Y, Perin J, Zhu J, et al. Global, regional, and national causes of under-5 
mortality in 2000-15: an updated systematic analysis with implications for the sustainable development goals. Lancet. 2016;388(I0063):3027-35

6. The United Nations Inter-agency Group for Child Mortality Estimation (UN IGME). Levels and trends in mortality. UN, New York, 20I5. https:// www.un.org/en/development/desa/population/ publications/mortality/child-mortality-report-20I5. asp Accessed March 14, 2019.

7. Aheto JMK. Predictive model and determinants of under-five child mortality: evidence from the 2014 Ghana demographic and health survey. BMC Public Health, 2019; 19(I), 64.

8. Global Burden of Diseases 2017 SDG Collaborators. Measuring progress from 1990 to 2017 and projecting attainment to 2030 of the health-related sustainable. Lancet. 2018 Nov 10;392(I0159):209I138.

9. Jeemo P, Mini GK, Thankappan KR, Sylaja P (20I8). GBD 2017 Mortality Collaborators. Global, regional, and national age-sex-specific mortality and life expectancy, 1950-2017: a systematic analysis for the Global Burden of Disease Study 2017. Lancet 2018; 2018 Nov 10;392(10I59):1684-1735.

10. Ghana Statistical Service, Ghana Health Service, ICF International. Ghana Demographic and Health Survey 20I4. Rockville: GSS, GHS, and ICF International; 2015. https://dhsprogram.com/pubs/ pdf/fr307/fr307.pdf.Accessed on March 14, 2019.

II. World Health Organization. Country health profile, 2012. Published 2012. www.who.int/whosis/country select.cfm. Accessed on March 12, 2019.

12. Blanchet NJ, Fink G, Osei-Akoto I. The effect of Ghana's National Health Insurance Scheme on health care utilisation. Ghana Medical Journal, 20I2; 46(2), 76-84.

13. Kipp AM, Blevins M, Haley CA, Mwinga K, Habimana $\mathrm{P}$, Shepherd BE,Vermund $\mathrm{SH}$. Factors associated with declining under-five mortality rates from 2000 to 2013: an ecological analysis of 46 African countries. BMJ Open, 2016; 6(I), e007675.

14. Tette EM, Nyarko MY, Nartey ET, Neizer ML, Egbefome A, Akosa F, Biritwum RB. Under-five mortality pattern and associated risk factors: a case-control study at the Princess Marie Louise Children's Hospital in Accra, Ghana. BMC Pediatrics, 2016; I6(I), I48.
15. Quansah E, Ohene LA, Norman L, Mireku MO, Karikari TK. Social factors influencing child health in Ghana. PloS ONE, 2016; I I (I), e0I4540I.

16. Kanmiki EW, Bawah AA, Agorinya I, Achana FS, Awoonor-Williams JK, Oduro AR, Akazili J. Socioeconomic and demographic determinants of under-five mortality in rural northern Ghana. BMC International Health and Human Rights, 20I4; I4(I), 24-34.

17. MosleyWH, \& Chen LC.An analytical framework for the study of child survival in developing countries. Population and Development Review, 1984; 10, 25-45.

18. Kennedy PA. Guide to Econometrics. Oxford, Blackwell: MIT Press; 2003.

19. Worku Z. Factors that affect under-five mortality among South African children: analysis of the South African Demographic and Health Survey Data Set. In: Proceedings of the World Congress on Engineering and Computer Science, 2009; 2, I-3.

20. Thaddeus S, Maine D. Too far to walk: maternal mortality in context. Social Science and Medicine, 1994; 38, I091-III0.

21. Government of Ghana. Brief policy appraisal of the free senior high school:2018. http:// www.nnedghana. org/2018/04/19/policy-brief-an-appraisal-of-thefree-senior-high-school-policy-in-ghana/ Accessed March 14, 2019.

22. Doctor HV. Does living in a female-headed household lower child mortality? The case of rural Nigeria. http://www.rrh.org.au/articles/subviewnew. asp? ArticlelD=1635. Accessed 12 March 2019

23. Kayode GA,AdekanmbiVT, Uthman OA. Risk factors and a predictive model for under-five mortality in Nigeria: evidence from Nigeria demographic and health survey. BMC Pregnancy Childbirth, 2012; $12,10$. https://doi.org/I0.1 I86/I47I-2393-12-10

24. Ghana Health Service (GHS). Community-based Health Planning and Services: Operational Policy, Ghana;2005

25. Hossain M, Islam M. Effects of Demographic and Household Variables on Infant and Child Underfive Mortality: An Application of Logistic Model. The Internet Journal of Health, 2008; (8), 2-I3.

26. Sahu D, Nair S, Singh L, Gulati BK, Pandey A. Levels, trends \& predictors of infant \& child mortality among Scheduled Tribes in rural India. Indian J Med Res, 2015; 4, 709-7I9 
27. National Health Insurance Authority (NHIA).Annual report 2009. Accra: National Health Insurance Authority, Ghana; 2010.

28. Byford-Richardson L,Walker M, MuckleW,SpragueA, Fergus S, Rennicks-White R,Dick B. Barriers to access of maternity care in Kenya: a social perspective. J Obstet Gynaecol Can. 2013;35(2):I25-30. https:// doi.org/I0.I0I6/SI70I-2I63(I5)3I0I6-I.

29. Ghana Health Service (GHS). Community-based Health Planning and Services: Operational Policy, Ghana;2005

30. World Health Organization. Health situation in the Americas: basic indicators. Washington DC: WHO. http://iris.paho.org/xmlui/handle// 23456789/34329 Accessed on 14 March 2019
PUBLISH IN THE

International Journal of Translational

Medical Reasearch and Public Health

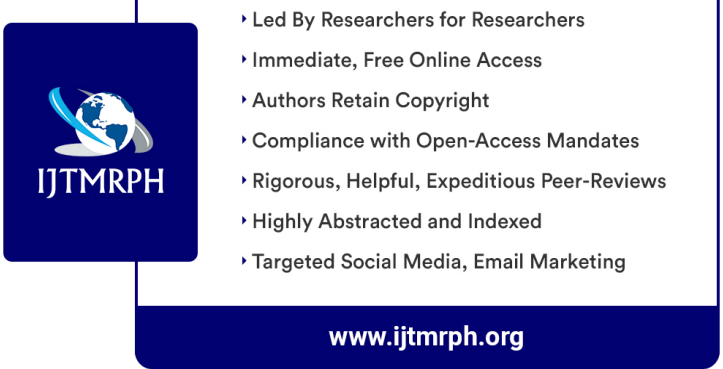

